\title{
A failure surface for circular footings on cohesive soils
}

\author{
H. A. TAIEBAT* and J. P. CARTER $\dagger$
}

The results of three-dimensional finite element analyses of circular footings under combinations of vertical load, horizontal load and moment are presented in this paper. The soil is assumed to be uniform and homogeneous and deforms under undrained conditions. These studies include the performance of the foundations under large overturning moments and large horizontal loads. The contact between the soil and the rigid footing is unable to sustain tension and therefore allowance is made for breakaway under large overturning moments. The results of the analyses are presented in the form of a failure locus in the vertical, horizontal and moment loading space. A comparison is made between the results of the current analysis and a simple method commonly used in calculation of the bearing capacity of foundations. It is shown that, while the hypothesis of an effective footing width provides a good approximation to the effects of load eccentricity, the conventional method overestimates the effects of load inclination for load combinations with a large horizontal shear component. A new factor is presented in this paper that can be used to describe the effects of load inclination more accurately when used with the simple method to calculate bearing capacity.

KEYWORDS: bearing capacity; circular foundation; failure surface; numerical modelling
Cette communication présente les résultats d'analyses aux éléments finis tridimensionnelles de semelles circulaires sous différentes combinaisons de charge vertical, charge horizontale et moment. Le sol est supposé être uniforme et homogène, et se déformer dans des conditions non drainées. Ces études portent également sur les performances des fondations en présence de moments de basculement de grande envergure, et de charges horizontales importantes. Le contact entre le sol et la semelle rigide n'est pas en mesure de supporter la tension; on prévoit, par conséquent, un dégagement pour le détachement sous l'effet de moments de basculement de grande envergure. Les résultats de ces analyses sont présentés sous forme de point de rupture dans l'espace de charge verticale, horizontale, et du moment. On effectue une comparaison entre les résultats de l'analyse en cours, et on utilise une simple méthode utilisée fréquemment dans le calcul de la force portante des fondations. Il est démontré qu'alors que l'hypothèse d'une largeur effective de la semelle fournit une bonne approximation des effets de l'excentricité de la charge, la méthode conventionnelle, elle, surestime les effets de l'inclinaison de la charge pour les combinaisons de charge avec une composante de cisaillement horizontal de grande envergure. La présente communication introduit un nouveau facteur que l'on peut utiliser pour décrire de façon plus précise les effets de l'inclinaison de la charge, lorsqu'il est utilisé avec la simple méthode de calcul de la force portante.

\section{INTRODUCTION}

Classical solutions for the bearing capacity of foundations are based on the original studies of a strip punch by Prandtl (1921) and Reissner (1924). These solutions have been modified to accommodate conditions such as load inclination, load eccentricity, footing shape and so on. The modifications are usually based on either limit equilibrium analyses or empirical approaches. For example, eccentricity of the load is commonly included in design using the effective width rule. The influence of load inclination is included most often by reducing the bearing capacity of the foundation against the vertical component of the load.

The existence of a unique or exact solution to the bearing capacity problem of circular foundations subjected to eccentric-inclined loading has not yet been demonstrated. In fact even for the simple case of strip footings, where upper bound and lower bound theorems and the method of characteristics can more readily be applied, the existence of an exact solution cannot be demonstrated because the normality condition is violated at the interface between the footing and the soil. A unique failure surface may no longer be defined for this case and the upper bound or the lower bound

Manuscript received 17 April 2007; revised manuscript 5 August 2009. Published online ahead of print 25 January 2010 .

Discussion on this paper closes on 1 September 2010, for further details see p. ii.

* The University of New South Wales, Sydney, Australia

$\dagger$ Faculty of Engineering and Built Environment, The University of Newcastle, Callaghan, Australia theorems may not be valid (Houlsby \& Puzrin, 1999). In the absence of a rigorous analytical solution, numerical methods may provide valuable information about the bearing capacity of foundations.

Attempts have been made previously to find a failure surface for shallow circular foundations on cohesive soils using the results of three-dimensional (3D) finite element (FE) analyses (e.g., Taiebat \& Carter, 2000; Gourvenec \& Randolph, 2002, 2003). In these papers unlimited tensile strength was assumed for the interface between the footing and soil and it was found that the failure locus in the $M-H$ plane is non-symmetric. The foundation shows a higher resistance when a horizontal load is applied above the ground level, generating a moment and a horizontal load at the foundation base. Taiebat \& Carter (2002a, 2002b) have shown that the effective width rule suggested by Meyerhof (1953) is a good approximation for strip and circular foundations subjected to eccentric loading. Taiebat \& Carter (2003) have shown that the failure surface for a circular foundation is more symmetrical when allowance is made for separation of the foundation and soil.

In this paper the results of a series of $3 \mathrm{D} \mathrm{FE}$ analyses of an effectively rigid circular footing resting on the surface of a uniform purely cohesive soil are presented. The footing was subjected to a comprehensive range of various combinations of vertical loads, lateral loads and moments. A special 'no-tension' interface has been used in the analyses to model the separation of the footing and the soil that may occur under large moments. The results of the numerical analyses have been used to find a failure envelope for the foundation. 
The FE results are also compared with the conventional bearing capacity equation and with the results of similar numerical analyses using an interface with unlimited tensile strength.

\section{CONVENTIONAL METHOD}

The effects of eccentricity and inclination of a load are included in calculation of the vertical bearing capacity of foundations based on the results of both limit equilibrium analyses and extensive laboratory experiments. Eccentricity of the load is commonly included in design using the effective width rule suggested by Meyerhof (1953) for strip footings. In this method, which has been widely accepted in geotechnical design practice, the area of the footing is reduced to that of a fictitious footing on which the load is concentric. If the shape of the original footing is circular, the fictitious footing is then replaced by an equivalent rectangular footing for which the bearing capacity can be calculated. The influence of the inclination of the load can also be included by reducing the bearing capacity of the foundation against the vertical component of the loading.

The bearing capacity of a circular footing resting on the surface of a purely cohesive soil can be calculated using the following expression (Vesic, 1973)

$$
V=\zeta_{\mathrm{i}} \zeta_{\mathrm{s}}(2+\pi) s_{\mathrm{u}} A^{\prime}
$$

In equation (1), $V$ is the ultimate vertical bearing capacity of the foundation, $\xi_{\mathrm{s}}$ and $\xi_{\mathrm{i}}$ are factors that consider the effects of the shape of the contact area between the soil and footing and the effects of the inclination of the load, respectively, $s_{\mathrm{u}}$ is the undrained shear strength of the soil and $A^{\prime}$ is the area of the fictitious footing, which takes into account the effect of load eccentricity. The effective area of a circular footing subjected to a vertical load, $V$, and an overturning moment, $M$, can be calculated as

$$
A^{\prime}=\frac{D^{2}}{2}\left(\cos ^{-1}\left(\frac{2 e}{D}\right)-\frac{2 e}{D} \sqrt{1-\left(\frac{2 e}{D}\right)^{2}}\right)
$$

where $D$ is the diameter of the circular footing and $e=M / V$ is the eccentricity of the vertical load (Fig. 1). The aspect ratio of the equivalent rectangular footing, $B^{\prime} / L^{\prime}$, can be approximated as the ratio $b / l$, as shown in Fig. 1 , that is

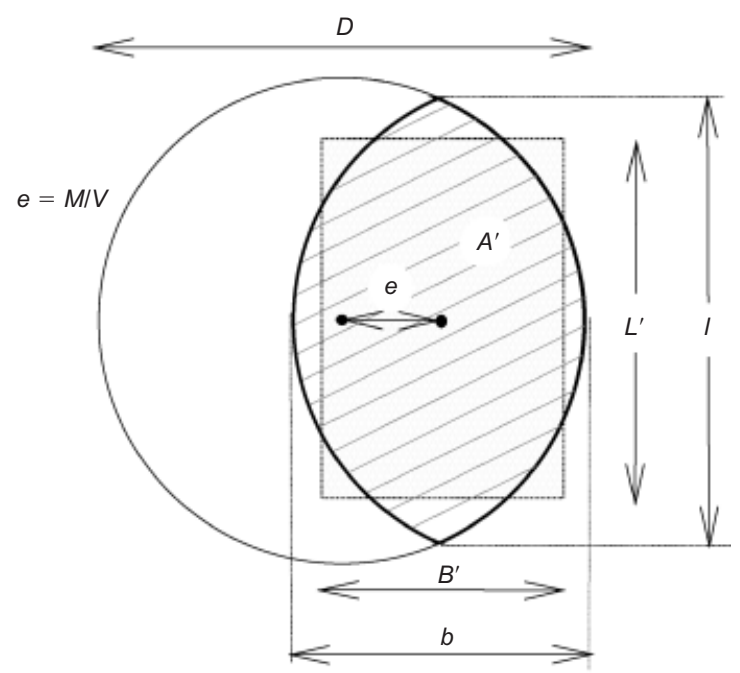

Fig. 1. Effective area of a circular footing

$$
\frac{B^{\prime}}{L^{\prime}}=\frac{b}{l}=\sqrt{\frac{D-2 e}{D+2 e}}=\sqrt{\frac{D V-2 M}{D V+2 M}}
$$

The shape factor for the equivalent rectangular footing is suggested by Vesic (1973) as

$$
\xi_{\mathrm{s}}=1+0 \cdot 2\left(\frac{B^{\prime}}{L^{\prime}}\right)
$$

The expression for inclination factor, $\zeta_{i}$, as recommended by Vesic (1973), is

$$
\xi_{\mathrm{i}}=1-\frac{\left(2+B^{\prime} / L^{\prime}\right) H}{\left(1+B^{\prime} / L^{\prime}\right) A^{\prime}(2+\pi) s_{\mathrm{u}}}
$$

where $H$ is the horizontal component of the applied load.

\section{FINITE ELEMENT IDEALISATION}

Consider a rigid circular footing with a diameter $D$ resting on the surface of a uniform homogeneous weightless soil that deforms under undrained conditions. The soil is assumed to be elastic-perfectly plastic obeying the Tresca failure criterion. It has a uniform undrained shear strength of $s_{\mathrm{u}}$ and an undrained Young's modulus of $E_{\mathrm{u}}=300 s_{\mathrm{u}}$. A Poisson's ratio of $v \approx 0.5(=0.49$ to avoid numerical difficulties) was assumed for the soil to approximate the constant volume response of the soil under undrained conditions. The footing is modelled as an elastic material with a Young's modulus of $E_{\mathrm{f}}=1000 E_{\mathrm{u}}$ and therefore it can be considered as effectively rigid.

The Tresca failure criterion has gradient discontinuities at the corners of its yield and plastic potential surfaces, which cause singularities in evaluation of the elasto-plastic stiffness matrix. Such discontinuities can be removed from the yield and plastic potential surfaces using different methods, but all approximate the true Tresca criterion around the discontinuities and also affect the flow rule. In all analyses described here a flow rule is selected which is very close to the Tresca criterion. The effects of the flow rule on the FE predictions were discussed separately by Taiebat \& Carter (2008).

The interface between the footing and the soil is unable to sustain tension. A thin layer of 'no-tension' elements was used under the footing to model the contact at the interface. Separation of the footing from the soil, at high moment, is signalled numerically by the occurrence of any vertical tensile stress greater than $0 \cdot 0001 s_{\mathrm{u}}$ at any Gauss point in the interface elements. Immediately after the separation no shear stress can be sustained in the interface elements. The unbalanced stresses that may exist at this stage in the interface elements were applied on the adjacent nodes and redistributed to the FE system. Flow of soil under the footing may cause the gap between the footing and soil, generated after separation, to close again. This occurs when the total vertical strain at any Gauss point in the interface elements becomes compressive, after which the interface element acts as a normal soil element which resists compressive and shear stresses.

The FE formulation used in the analyses is based on the 'semi-analytical' approach in FE modelling described by Zienkiewicz \& Taylor (1989), which is an efficient tool for $3 \mathrm{D}$ analyses. In this method advantage is taken of the axisymmetric nature of the problem geometry. The cylindrical geometry is divided into $M$ identical wedges, as shown in Fig. 2. In this case the body exhibits a polar periodicity with period $M$. Therefore, any function $g$ of the discrete variable $j$, defined in the $M$ wedges satisfies

$$
g_{j}=g_{j \pm k M} \text { for } k=1,2, \ldots
$$




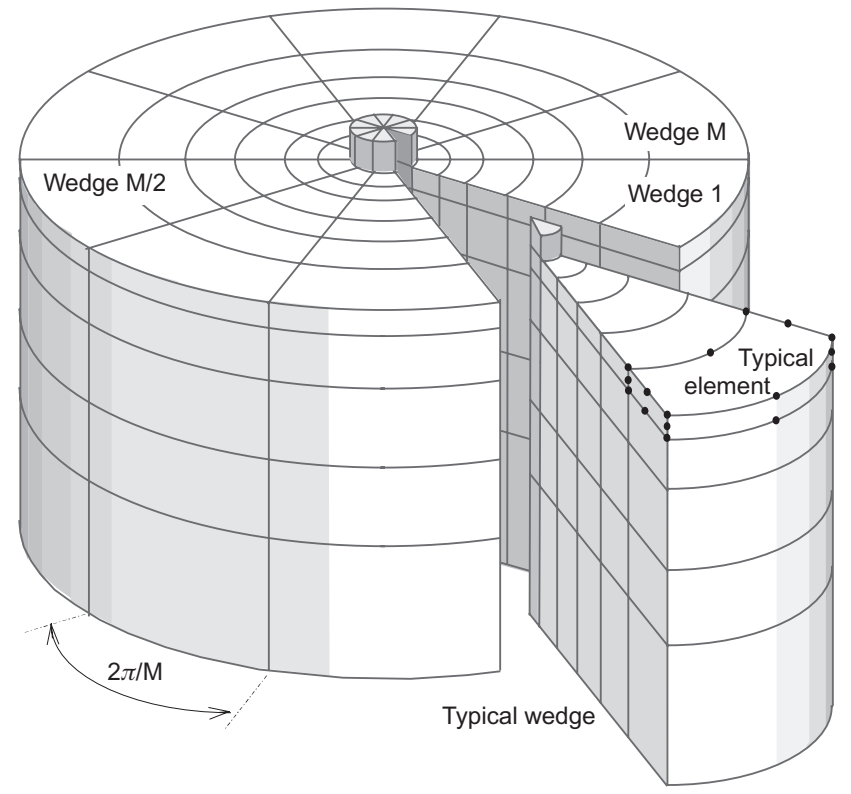

Fig. 2. Typical arrangement of wedges and elements in finite element idealisation

A periodic function such as $g_{j}$ can be represented in the discrete Fourier form as

$$
g_{j}=\frac{1}{\sqrt{M}} \sum_{k=0}^{M-1} G_{k} \mathrm{e}^{i j k \alpha}
$$

where $\alpha$ is equal to $2 \pi / M$ and $G_{k}$ are the Fourier coefficients given by

$$
G_{k}=\frac{1}{\sqrt{M}} \sum_{j=0}^{M-1} g_{j} \mathrm{e}^{-i j k \alpha}
$$

With the above definition, the displacement and load vectors may also be written in terms of their Fourier coefficients as

$$
\left(u_{j}, f_{j}\right)=\frac{1}{\sqrt{M}} \sum_{k=0}^{M-1}\left(U_{k}, F_{k}\right) \mathrm{e}^{i j k \alpha}
$$

where $u_{j}$ and $f_{j}$ denote nodal displacements and nodal forces applied to wedge $j$, respectively. $U_{k}$ and $F_{k}$ are the $k^{\text {th }}$ Fourier coefficients of the nodal displacements and nodal forces given by

$$
\left(U_{k}, F_{k}\right)=\frac{1}{\sqrt{M}} \sum_{j=0}^{M-1}\left(u_{j}, f_{j}\right) \mathrm{e}^{-i j k \alpha}
$$

Formulation of the stiffness matrix and FE equations based on the discrete Fourier representations of field quantities results in a modal set of equations

$$
\sum_{k=0}^{M-1} S_{k} U_{k}=\sum_{k=0}^{M-1} F_{k}
$$

Equation (10) defines $M$ sets of the load-deformation relationships for the axi-symmetric body in discrete Fourier space. A solution to this equation gives the Fourier coefficients of the nodal displacements $U_{k}$, from which the nodal displacements can be obtained using equation (8). It is noted that all the effects of non-linear material response are incorporated in the right hand side of equation (10) in a manner similar to that of the initial stress method of more conventional non-linear FE analysis. Formulation of 3D FE equation in this way has the effect of considerably reducing the necessary time for solving three-dimensional problems. Instead of solving a very large number of algebraic equations for the full $3 \mathrm{D}$ problem, a smaller number of equations arising from each of a discrete number of substitute problems are solved. Further details of the semi-analytical method used in this study may be found in Taiebat \& Carter (2001). Application of this method to a number of geotechnical problems has shown no adverse effect on the accuracy of the FE solutions (Taiebat, 1999).

The FE mesh used in the analyses represents 24 wedgeshaped segments over $360^{\circ}$ in the circumferential direction, each consisting of 698 isoparametric (20 node) brick elements. A portion of the FE mesh close to the foundation is shown in Fig. 3. The mesh under the footing consists of equally spaced FEs in the radial and circumferential directions. The boundaries are set at a distance of about $4 D$ from the footing to avoid any significant influence on the response of the foundation.

The sign conventions for vertical load, horizontal load and moment used in this study are based on the right-handed axes and clockwise-positive conventions, $(V, M, H)$, as described by Butterfield et al. (1997) and as shown in Fig. 3.

\section{METHOD OF ANALYSIS}

Various combinations of loads and moment were used in a series of FE analyses to investigate the shape of the failure envelope for the foundation in $(V, M, H)$ space. The shape of the failure envelope was obtained mainly by the results of analyses performed under displacement-defined conditions. The shape of the failure envelope was verified by the results of analyses under a modified version of 'swipe' loading, and also under load-defined conditions.

Side swipe was originally introduced by Tan (1990) as an experimental technique and later used by some researchers (e.g., Bell, 1991; Martin, 1994; Bransby \& Randolph, 1998; Gourvenec \& Randolph, 2003) where a foundation is loaded to failure in one direction first followed by loading in a second direction. The load path produced during the second portion of loading was shown to be close to the failure envelope in the two loading directions (Bransby \& Randolph, 1998), although the loading in the second direction is monotonic, that is the incremental displacement is unidirectional. Gourvenec \& Randolph (2003) applied the side swipe loading method in a series of numerical analyses and showed that while side swipe loading works well in some cases, swipe tests in general have to be chosen with care. One of the fundamental assumptions inherent in a side swipe test is that during the second portion of loading the reduction in elastic deformation in the first direction is equal to the increase in plastic deformation in the same direction.

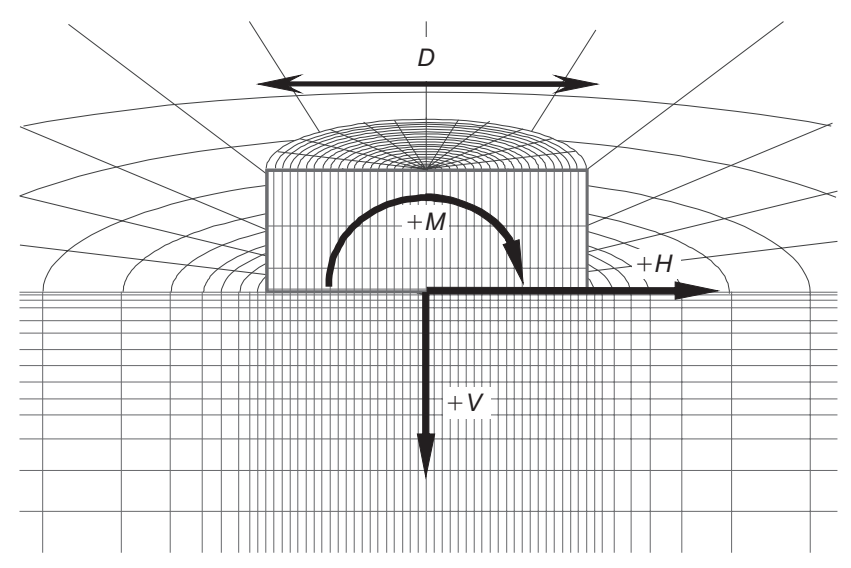

Fig. 3. Conventions for positive loads and moment 
If the elastic deformation becomes greater than the plastic deformation, the load path moves inside the true failure envelope.

In order to improve the accuracy of the predicted failure path in swipe loading, the incremental displacement in the first direction is reduced gradually during the second portion of loading while the incremental displacements in the second and third directions increase from zero. In this case a plastic deformation greater than the elastic one in the first direction is maintained while the plastic deformation in the second direction is being developed, and therefore normality is valid over the whole load path and the load path can theoretically stay on the failure surface. The modified swipe loading is applied in the present studies, where the foundation is loaded vertically to failure and then, in the second portion of loading, the incremental vertical displacement, $\delta_{\mathrm{v}}$, reduces from its maximum value (downwards positive) using a cosine function. The incremental horizontal displacement, $\delta_{\mathrm{h}}$, and the incremental rotation, $\delta_{\theta}$, increase from zero using a sine function. When $\delta_{\mathrm{v}}$ reaches zero, $\delta_{\mathrm{h}}$ and $\delta_{\theta}$ reach their maximum values. After this stage $\delta_{\mathrm{v}}$ becomes negative (upwards) while $\delta_{\mathrm{h}}$ and $\delta_{\theta}$ reduce to zero at the end of the analysis. Different ratios of $\delta_{\mathrm{h}} / \delta_{\theta}$ can be used to obtain various load paths that cover most of the failure surface. These types of analyses are highly efficient since their load paths lie entirely on the yield or failure surface for the footing. The only problem with this type of swipe analyses is that there is less control over the load paths generated from the analysis. The load paths may not cover the whole failure surface unless different functions are tried to vary $\delta_{\mathrm{v}}, \delta_{\mathrm{h}}$ and $\delta_{\theta}$.

The failure surface constructed by the results of the modified swipe analyses matches well that constructed by the displacement controlled analyses. The load paths generated by the modified side swipe loading have been found to be on the failure surface for all cases considered in the present studies. Only when the values of $\delta_{\mathrm{h}}$ and $\delta_{\theta}$ become very small, does the side swipe analysis lose its accuracy.

Typical load-displacement curves obtained from a FE analysis under side swipe loading are presented in Fig. 4. In this analysis the foundation is brought to failure under a vertical displacement of $0.075 \mathrm{D}$ after which horizontal displacement and rotation are applied to the foundation. The load paths in $V-H$, and $M-H$ loading planes obtained from one of the side swipe analyses are presented in Fig. 5.

Figure 6 shows the load paths generated by swipe loading analyses and failure points obtained by displacement-defined and load-defined analyses in $V-H$ and $V-M$ loading planes. The displacement defined analyses are considered to result in the most accurate failure points and are therefore used to construct a failure surface for the foundation. Additional

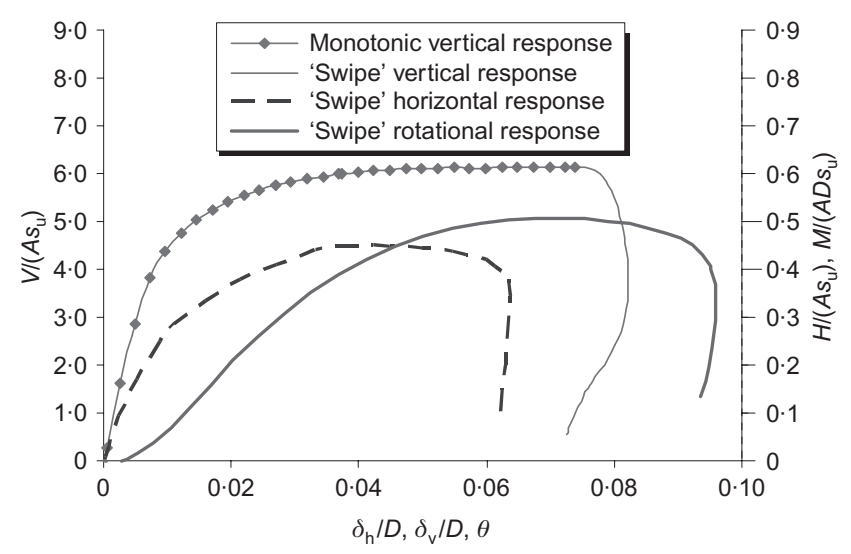

Fig. 4. Typical load-displacement curves

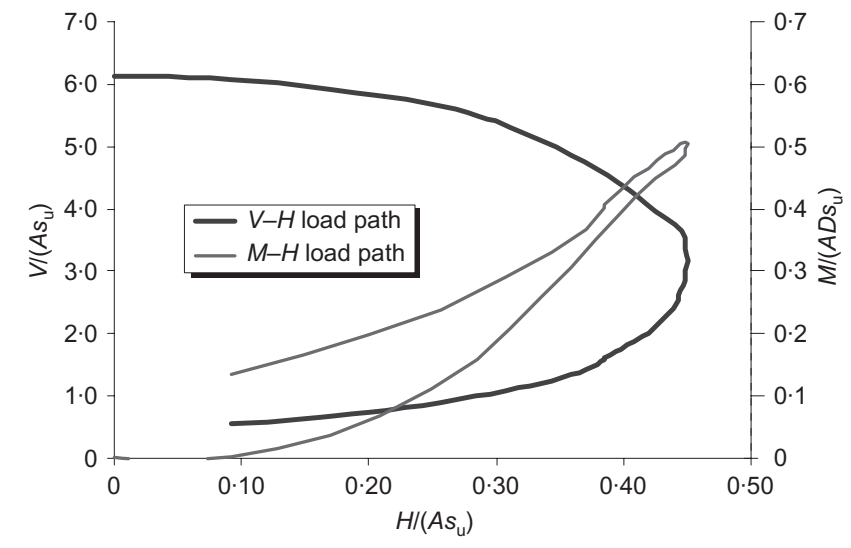

Fig. 5. Typical load paths in $M-H$ and $V-H$ loading planes
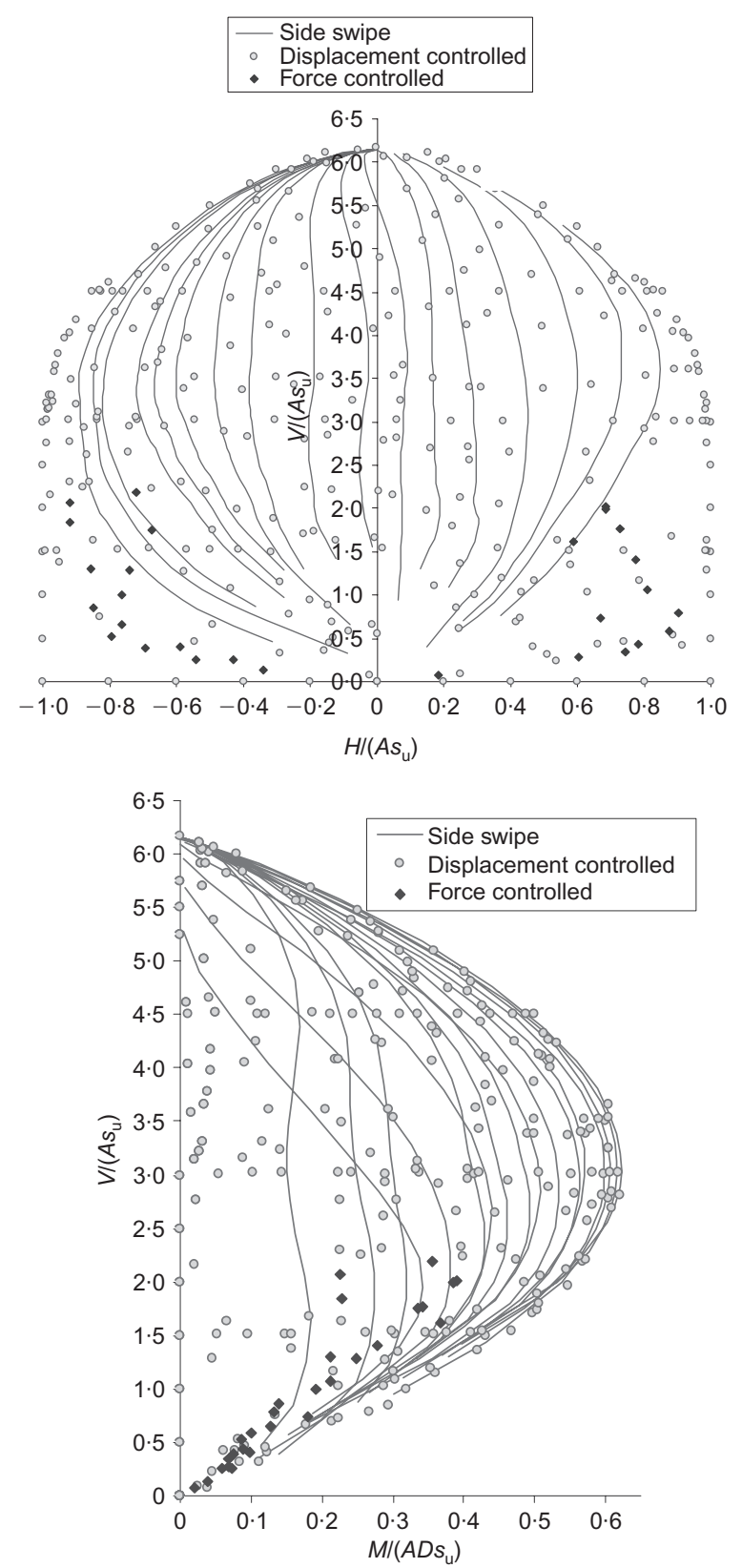

Fig. 6. Typical load paths in $M-H$ and $V-M$ loading planes

failure points have been obtained from load-defined analyses to cover areas not included in the displacement-defined analyses. The load paths from side swipe analyses are used to check the overall shape of the failure surface. 


\section{FINITE ELEMENT RESULTS}

The results of the numerical analyses have been used to approximate a 3D failure surface for the foundation. The 3D failure surface was constructed based on a triangulation scheme involving linear interpolation between predicted data points. A 3D image of the failure surface is presented in Fig. 7. The failure surface can be imagined as a slightly non-symmetric scallop. Only one side of the scallop, which includes positive moment, is shown in Fig. 7. Contours of equal moments on the failure surface, which evolve from a half circular-half rectangular shape at $M=0 \cdot 0$ to a shape close to a full circle at the maximum moment capacity, are shown in Fig. 8. A reason for the slight non-symmetrical appearance of the failure envelope may well be attributable to the FE approximation. However, there is no reason to suggest that a foundation under a combination of loads and moment should exhibit the same failure mechanism if the direction of the horizontal load changes, in which case some asymmetry may be expected.

The failure locus provides a convenient way to investigate the undrained bearing capacity of a foundation under combined loading. Graphical display of the failure locus presents a clear image of the safety margin of a foundation under any specific combination of loads and moment, and the consequences of any change in the loading. A foundation with a small vertical load is most vulnerable to moment, as may be expected. Indeed a foundation with a zero vertical load does not have any resistance to moment loading and any increase in vertical load results in a larger moment

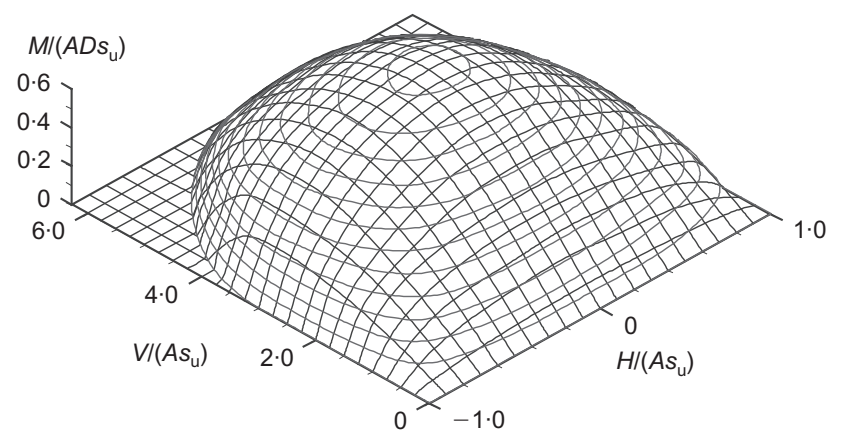

Fig. 7. Three-dimensional failure envelope in $V-M-H$ loading space

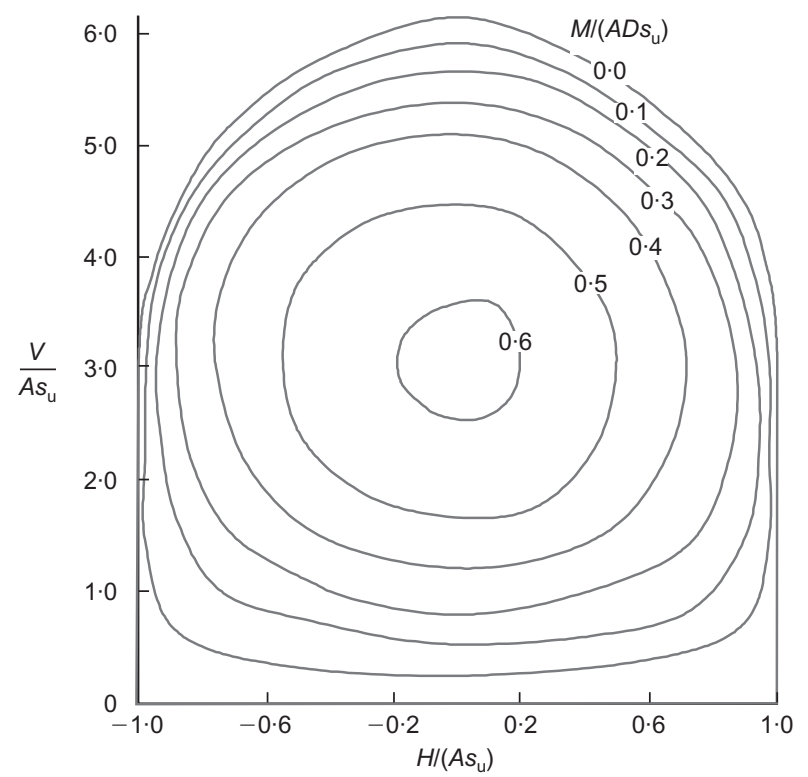

Fig. 8. Contours of moment capacity in $V-H$ loading space capacity for the foundation. A vertical load below $0.5 V_{\text {ult }}$, where $V_{\text {ult }}$ is the capacity of the foundation under purely vertical loading, can be safely increased to $0 \cdot 5 V_{\text {ult }}$ if the moment and horizontal load applied to the foundation are kept constant. However, if the vertical load is greater than $0.5 V_{\text {ult }}$, any increase in vertical load requires a decrease in horizontal load or moment in order to sustain the same factor of safety.

\section{COMPARISON OF RESULTS}

A 3D image of the failure surface obtained from numerical analyses of a footing with full under-base tensile strength is presented in Fig. 9. This failure envelope is very similar to the one obtained previously by Taiebat \& Carter (2000). The accuracy of the failure envelope has been increased in the current studies using a finer FE mesh and selection of a flow rule closer to the Tresca criterion, as discussed previously. The failure surface is non-symmetric; the foundation shows a higher resistance when the moment and horizontal load on the foundation are both positive. Full under-base adhesion between the soil and the footing preserves the moment capacity at low vertical load. Fig. 10 shows the failure envelope in the $M-H$ loading plane at zero vertical load together with the direction of 'flow' (i.e. foundation movement) at selected failure points. The maximum moment capacity occurs where the vertical load is zero and the horizontal load is about $0 \cdot 8 A s_{\mathrm{u}}$. The failure envelope in the $V-M-H$ space obtained assuming zero tensile strength at the interface between the soil and the footing is compared with the failure envelope assuming full under-base tensile strength in Fig. 11. Cross-sections of the failure envelopes at different vertical loads are also compared in Fig. 12. The failure envelope for the foundation with a 'no-tension' interface is smaller and located at one corner of the larger failure

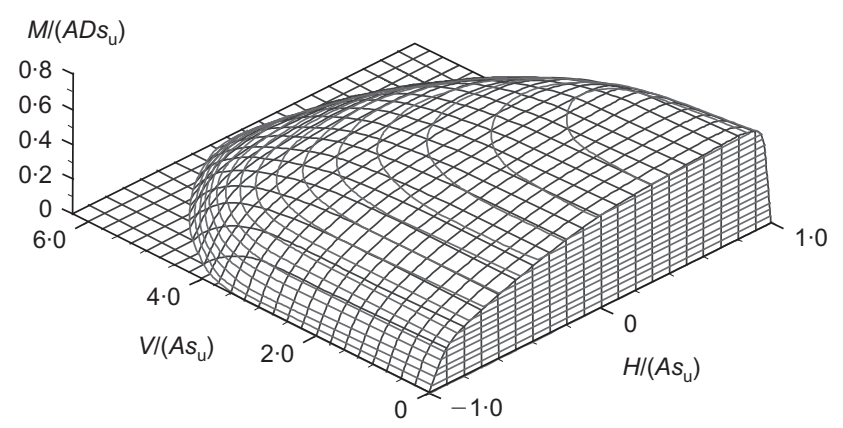

Fig. 9. Three-dimensional failure envelope, interface with full adhesion

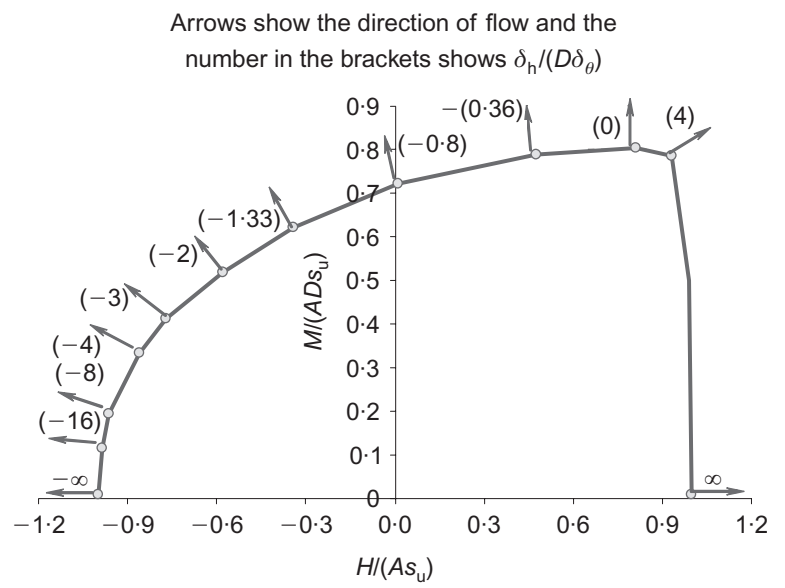

Fig. 10. Failure envelope in $M-H$ loading plane at $V=0$, full base adhesion 


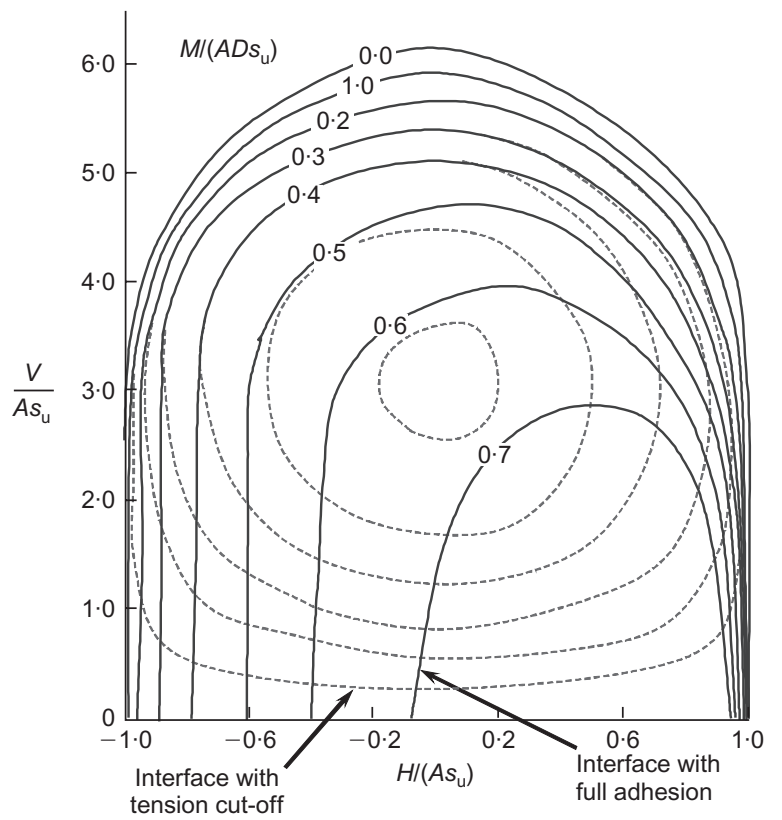

Fig. 11. Comparison of failure envelopes using two different interfaces between the soil and the footing

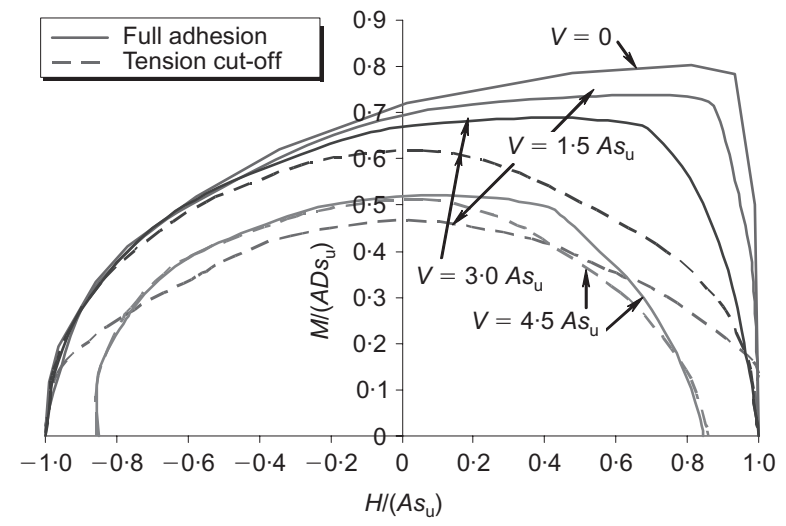

Fig. 12. Sections of failure envelopes with different interfaces

envelope predicted assuming full adhesion for the interface. The failure surface for foundations with a 'no-tension' interface is only slightly non-symmetric compared with the highly non-symmetric failure envelope obtained for the footing with unlimited tensile strength at its interface.

A 3D image of the failure envelope given by the conventional method of bearing capacity calculation, as described by Vesic (1973), is presented in Fig. 13. This failure envelope is compared with the failure envelope obtained

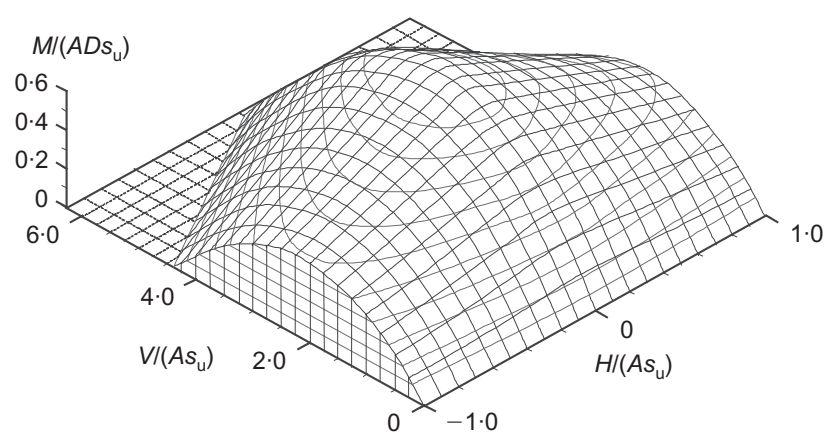

Fig. 13. Three-dimensional failure envelope, conventional method, Vesic (1973) from the current numerical analysis in Figs 14 and 15. The shaded area in Fig. 14 shows load combinations for which the conventional method overestimates the ultimate collapse load. In particular, the conventional method provides larger (non-conservative) failure values for load combinations consisting of high horizontal load and/or low vertical load components. However, in general, the conventional method is conservative and underestimates the collapse load for most practical load combinations. The degree of conservatism reaches maximum at load combinations consisting of vertical loads of $5-5 \cdot 5 A s_{\mathrm{u}}$ and horizontal loads of $\pm(0 \cdot 6-0 \cdot 4) A s_{\mathrm{u}}$ where the conventional method suggests zero moment capacity while the FE analyses gives a moment capacity of about $0 \cdot 2 A D s_{\mathrm{u}}$.

The failure envelopes in the $V-M$ plane at $H=0$, determined from the numerical analyses and the conventional method, are compared in Fig. 16. The conventional method gives a slightly conservative value for the maximum moment capacity of the foundation. For the case of a no-tension interface, the maximum moment predicted by the numerical analyses is $0.62 A D s_{\mathrm{u}}$, about $5 \%$ higher than that given by the conventional method, which is $0.587 A D s_{\mathrm{u}}$. The failure

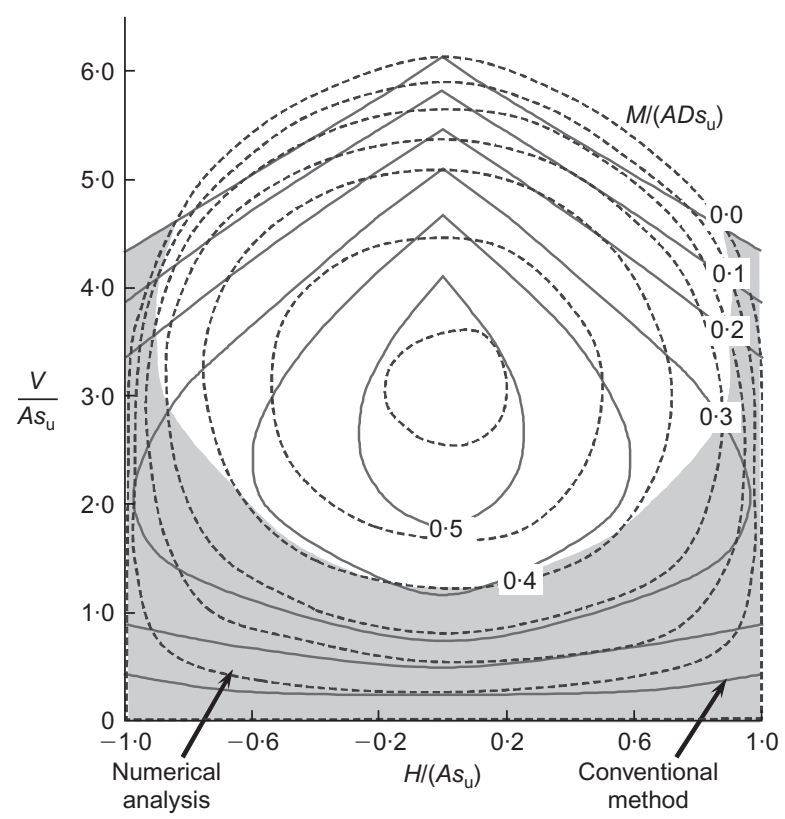

Fig. 14. Comparison of the failure envelope obtained from numerical analyses and the failure envelope given by the conventional method

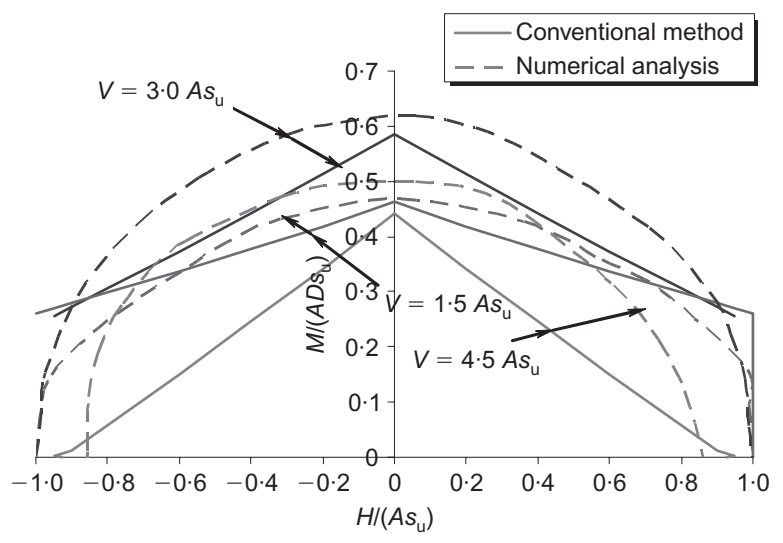

Fig. 15. Sections of failure envelopes given by conventional method and numerical analysis 


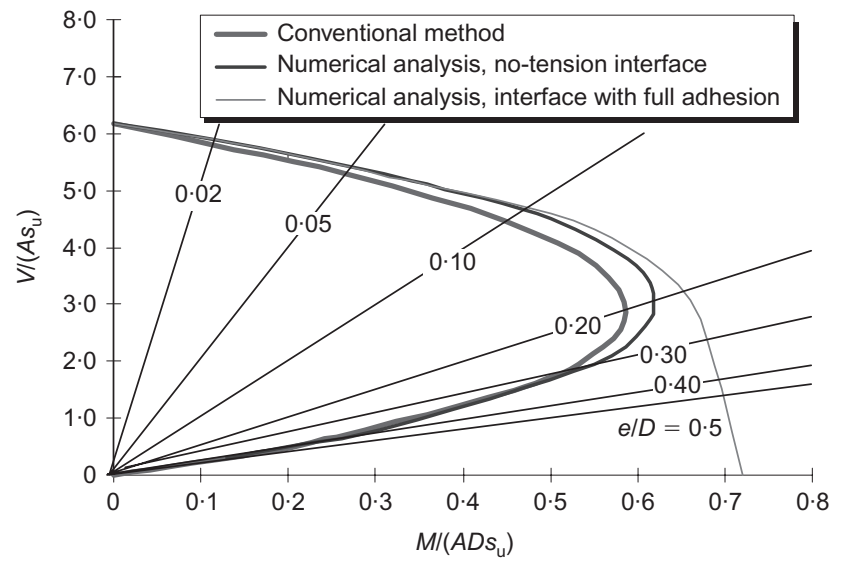

Fig. 16. Comparison of failure loci in a $V-M$ loading plane at $H=0 \cdot 0$

envelope obtained using a 'no-tension' interface departs from the failure envelope obtained from the numerical analysis using an interface with unlimited tensile strength at around $M=0.5 A D s_{\mathrm{u}}$. The ultimate moment capacity at $V=0$ increases from zero to about $M=0.72 A D s_{\mathrm{u}}$ when the tensile strength of the interface increases from zero to an unlimited value.

Note that based on Vesic's recommendation the shape factor for circular footings under pure vertical load is 1.2 and therefore the ultimate vertical capacity of the foundation is predicted to be $6 \cdot 17 A s_{\mathrm{u}}$. However, exact solutions for the vertical bearing capacity of circular footings on uniform Tresca soil (Eason \& Shield, 1960) suggest the ultimate bearing capacity of $6.05 A s_{\mathrm{u}}$ for footings with a rough base. The ultimate vertical capacity of $V_{\mathrm{ult}}=6 \cdot 166 \mathrm{As}$ u predicted by the FE procedure described here is slightly above the exact solution but approximately equal to Vesic's recommendation. This value is also within the upper bound solution of $6 \cdot 227 A s_{\mathrm{u}}$ and lower bound solution of $5 \cdot 856 A s_{\mathrm{u}}$ obtained by Salgado et al. (2004).

A non-dimensional representation of the failure loci at $H=0$ is shown in Fig. 17. This figure reveals that the results of the numerical analyses with a 'no-tension' interface are very close to and marginally higher than the conventional failure locus. Previous studies on the bearing capacity of eccentrically loaded smooth strip footings on cohesive soils, based on the kinematic approach of limit analysis, conducted by Michalowski \& You (1998), also resulted in failure loads which are marginally larger than

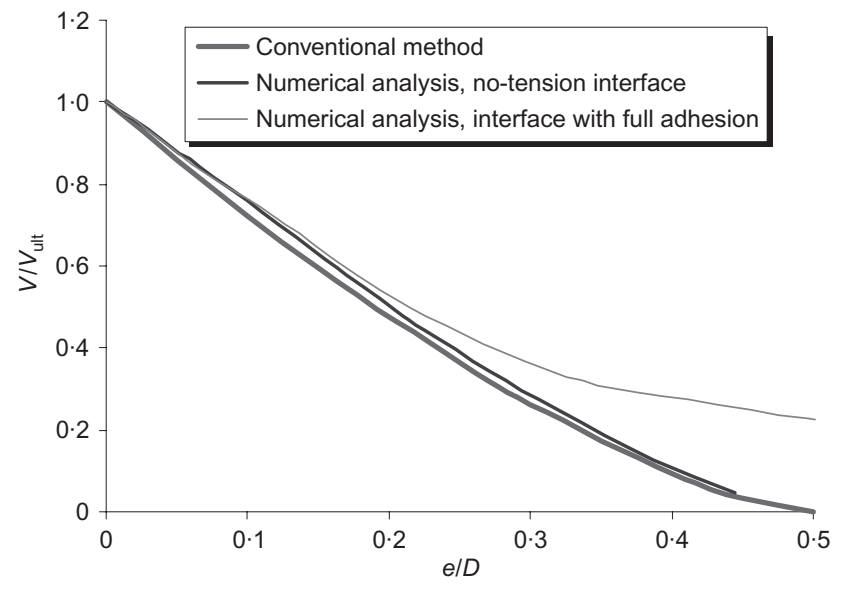

Fig. 17. Non-dimensional failure loci in the $V-M$ loading plane at $H=0 \cdot 0$

those given by the effective area rule. Unlike strip footings, application of the effective area rule to circular foundations does not yield a linear relationship between vertical capacity and eccentricity. For very small eccentricity the assumption of different interface models does not have any significant effect on the results of the numerical analyses. The influence of the interface condition becomes significant when $e / D>0.2$ and increases with an increase in eccentricity. The assumption of full adhesion between the soil and the footing results in a substantial vertical capacity at $e / D=0 \cdot 5$, that is when the load is at one edge of the footing.

The effective area rule is a convenient but simplified approach to include the effects of load eccentricity. The shapes of the effective area of the footing are superimposed on the contact area at failure obtained from the FE analyses in Fig. 18 for three different eccentricities. The similarities between the areas are significant. However, for any eccentricity the contact area predicted by the FE analyses is larger than the effective area, which contributes towards the larger prediction of the moment capacity by the numerical analysis.

\section{NEW INCLINATION FACTOR}

By comparing the conventional failure envelope with the one predicted numerically, it is evident that application of the effective area rule is an excellent approximation for including the effects of load eccentricity, while more work needs to be done to incorporate the effects of load inclination more accurately.

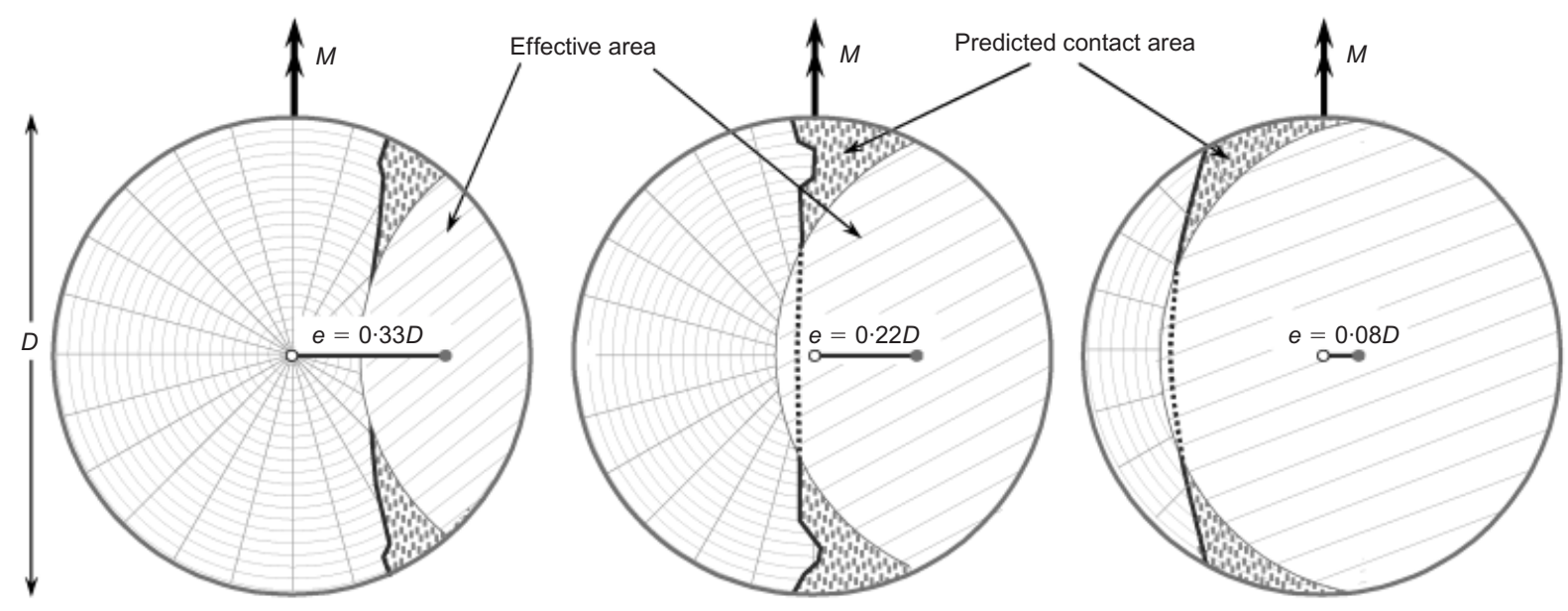

Fig. 18. Comparison of the contact area predicted by numerical analysis and the effective area 
The results of the numerical analyses show a parabolic variation of vertical bearing capacity with respect to the horizontal load in the upper half of the failure surface. Therefore, a new expression for inclination factor, $\zeta_{i}$, with a parabolic variation is suggested as

$$
\zeta_{\mathrm{i}}=1-\frac{A}{2 A^{\prime}}\left(1-\sqrt{1-\left(\frac{H}{A s_{\mathrm{u}}}\right)^{2}}\right)
$$

It is suggested that the conventional expression for the inclination factor, equation (5), should be replaced by the proposed expression, equation (11), and then used in conjunction with equation(1) to include the effects of load inclination more adequately. Equations (1), (4) and (11) could be combined to form a single equation for the bearing capacity of circular footings on purely cohesive soils. A graphical representation of the failure envelope obtained in this way is presented in Fig. 19, where it is compared with the failure envelope using the inclination factor suggested by Vesic (1973), equation (5). Generally, the proposed inclination factor results in a higher bearing capacity for footings except for load combinations with a large component of horizontal load.

The failure envelope generated by the new inclination factor is very similar to the one obtained by the numerical analyses, and a comparison of them is given in Fig. 20. The failure envelope for the new inclination factor was normalised by the maximum moment capacity of the foundation obtained by the numerical analysis, that is $0.62 A D s_{\mathrm{u}}$, so that both envelopes have the same maximum moment capacity.

\section{CONCLUSIONS}

To investigate the shape of the undrained failure locus for the foundation, 3D FE analyses of rigid circular footings on a homogeneous, purely cohesive soil have been performed. The interface between the footing and the soil cannot sustain tension. The results of the numerical analyses reveal a scallop shape for the failure envelope. This failure envelope is attached to one corner of a larger failure envelope

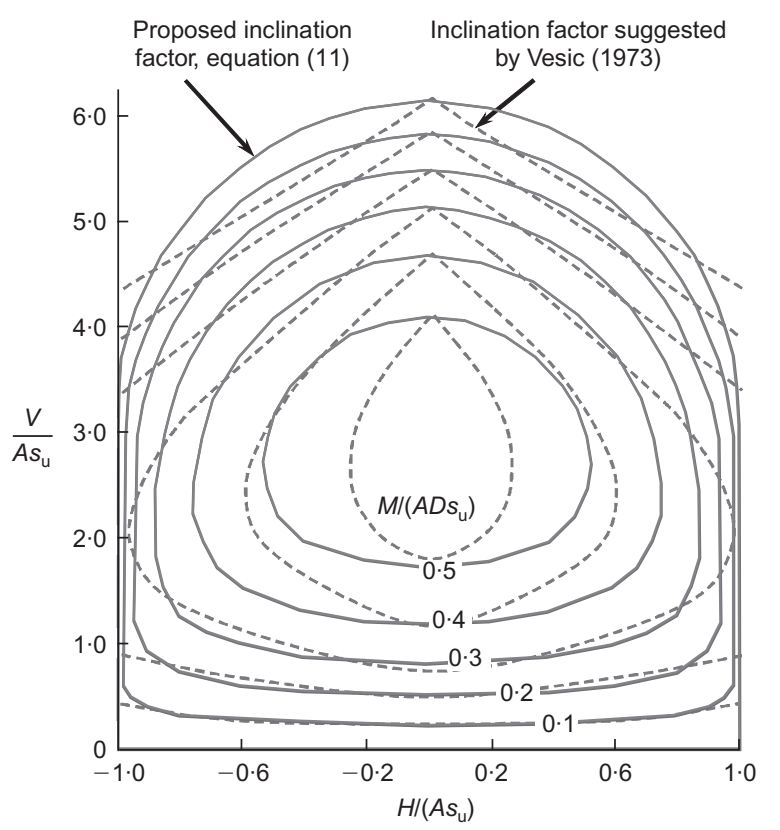

Fig. 19. Comparison of the failure envelopes obtained by the proposed inclination factor, equation (11) and the inclination factor suggested by Vesic, equation (5)

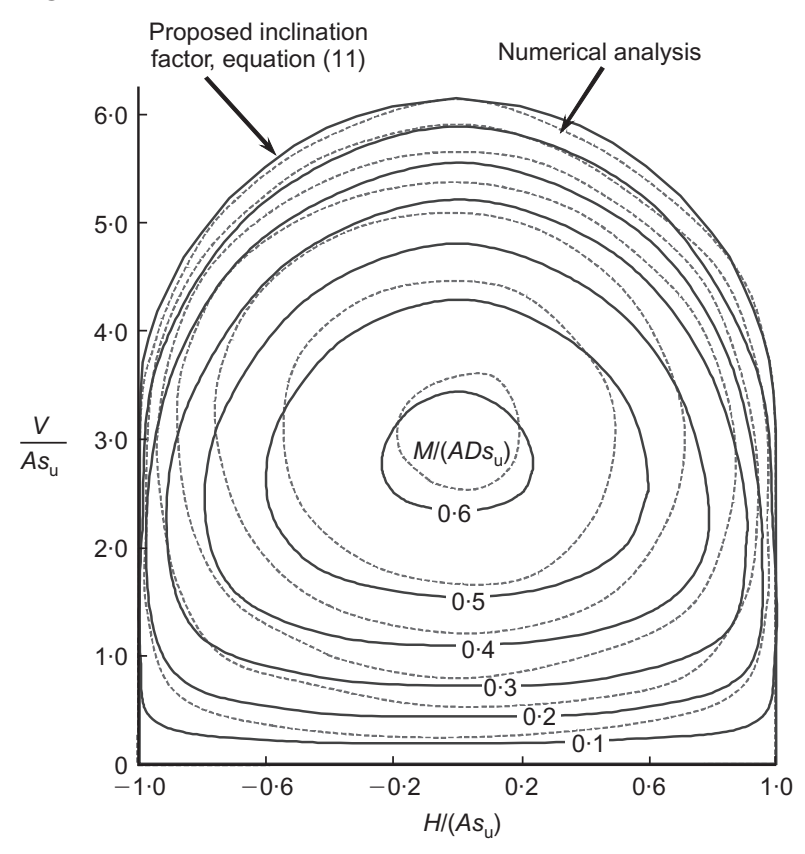

Fig. 20. Comparison of the failure envelopes obtained by the proposed inclination factor and the results of numerical analysis

obtained when unlimited tensile strength is assumed for the interface between the footing and the soil.

Comparison of the results of the numerical analyses with the conventional method, commonly used in the calculation of bearing capacity, indicates that the conventional method overestimates the failure load for load combinations with large horizontal components and/or low vertical components. Otherwise the conventional method underestimates the capacity of the foundations for most practical load combinations. This is primarily attributable to overestimation of the effects of horizontal loads on the vertical capacity of the foundation. This study also indicates that the conventional method of including the effects of eccentricity, based on the effective area rule of Meyerhof, yields an excellent approximation to the capacity of circular footings on cohesive soils. Only for significant bonding (adhesion) at the soil-footing interface and for large eccentricity does the effective area rule become overly conservative.

A new expression for the load inclination factor, equation (11), has been presented in this paper, and it can be used in conjunction with the effective area rule to include the effects of eccentricity and inclination of the load more adequately in calculation of the bearing capacity of circular foundations.

\section{REFERENCES}

Bell, R. W. (1991). The analysis of offshore foundations subjected to combined loading. MSc thesis, University of Oxford, UK.

Bransby, M. F. \& Randolph, M. F. (1998). Combined loading of skirted foundations Géotechnique 48, No. 5, 637-655.

Butterfield, R., Houlsby, G. T. \& Gottardi, G. (1997). Standardized sign conventions and notation for generally loaded foundations. Géotechnique 47, No. 5, 1051-1054.

Eason, G. \& Shield, R. T. (1960). The plastic indentation of a semiinfinite solid by a perfectly rough circular punch. J. Appl. Math. Phys. 11, No. 1, 33-43.

Gourvenec, S. \& Randolph, M. F. (2002). Three-dimensional finite element analysis of combined loading of skirted foundations on non-homogeneous clay. Proc. 8th Int. Symp. Numerical Models in Geomechanics, NUMOG VIII, Rome, 439-444.

Gourvenec, S. \& Randolph, M. F. (2003). Effect of strength nonhomogeneity on the shape of failure envelopes for combined 
loading of strip and circular foundations on clay. Géotechnique 53, No. 6, 575-586.

Houlsby, G. T. \& Puzrin, A. M. (1999). The bearing capacity of strip footing on clay under combined loading. Proc. R. Soc. 455A, 1983, 893-916.

Martin, C. M. (1994). Physical and numerical modelling of offshore foundations under combined loads. $\mathrm{PhD}$ thesis, University of Oxford, UK.

Meyerhof, G. G. (1953). The bearing capacity of foundations under eccentric and inclined loads. Proc. 3rd Int. Conf. Soil Mech. Found. Engng., Zurich 1, 440-445.

Michalowski, R. L. \& You, L. (1998). Effective width rule in calculations of bearing capacity of shallow footings. Comput. Geotech. 23, No. 4, 237-253.

Prandtl, L. (1921). Uber die Eindringungsfestigkeit plastisher Baustoffe und die Festigkeit von Schneiden. Z. Angew. Math. Mech. 1, No. 1, 15-20.

Reissner, H. (1924). Zum Erddruckproblem. Proc. 1st Int. Conf. Appl. Mech, Delft, 295-311.

Salgado, S., Lyamin, A. V., Sloan, S. W. \& Yu, H. S. (2004). Twoand three-dimensional bearing capacity of foundations in clay. Géotechnique 54, No. 5, 297-306.

Taiebat, H. A. (1999). Three-dimensional liquefaction analysis of offshore foundations. $\mathrm{PhD}$ thesis, The University of Sydney, Australia.
Taiebat, H. A. \& Carter, J. P. (2000). Numerical studies of the bearing capacity of shallow foundations on cohesive soil subjected to combined loading. Géotechnique 50, No. 4, 409-418.

Taiebat, H. A. \& Carter, J. P. (2001). A semi-analytical finite element method for three-dimensional consolidation analysis. Comput. Geotech. 28, No. 1, 55-78.

Taiebat, H. A. \& Carter, J. P. (2002a). Bearing capacity of strip and circular foundations on undrained clay subjected to eccentric loads. Géotechnique 52, No. 1, 61-64.

Taiebat, H. A. \& Carter, J. P. (2002b). A failure surface for the bearing capacity of circular footings on saturated clays. Proc. 8th Int. Symp. Numer. Models Geomech., NUMOG VIII, Rome, $457-462$.

Taiebat, H. A. \& Carter, J. P. (2003). Contact between soil and circular foundations under eccentric loading. Proc. 2nd MIT Conf. Comput. Fluid and Solid Mech., Cambridge 1, 674-677.

Taiebat, H. A. \& Carter, J. P. (2008). Flow rule effects in Tresca model. Comput. Geotech. 35, No. 3, 500-503

Tan, F. S. (1990). Centrifuge and theoretical modelling of conical footings on sand. $\mathrm{PhD}$ thesis, Cambridge University, UK.

Vesic, A. S. (1973). Analysis of ultimate loads of shallow foundations. J. Soil Mech. Found. Div. ASCE 99, SM1, 45-73.

Zienkiewicz, O. C. \& Taylor, R. L. (1989). The finite element method, 4th edn. New York: McGraw-Hill. 